LOBENZART disodium (CCA) is a novel immunomodulatory drug useful in the treatment of chronic inflammations. Its principal mechanism of action seems to be through enhancing the $T$ suppressor/ $T$ helper lymphocyte ratio. However, the molecular basis for these actions remains unclear. In this study it was found that CCA inhibits the production of guanosine $3^{\prime}, 5^{\prime}$-cyclic monophosphate almost completely when present in concentrations of $1 \mathrm{mM}$. Further results demonstrated that such inhibition could also be explained by interference in constitutive nitric oxide generation. In addition to previous findings, more insight into the molecular mechanism of action of CCA is provided.

Key words: Anti-inflammatory action, cGMP, Chronic inflammation, Immunomodulator, Lobenzarit disodium, Molecular mechanism, Nitric oxide.

\section{Lobenzarit disodium inhibits the constitutive NO-cGMP metabolic pathways. Possible involvement as an immunomodulatory drug}

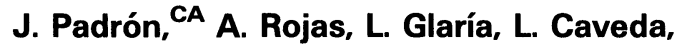 \\ R. Delgado, M. Torres, O. Martínez, E. López, \\ A. Beltrán and M. Palacios
}

Center of Pharmaceutical Chemistry, Department of Pharmacology and Toxicology, POB 6990, Havana City, Cuba

${ }^{\mathrm{CA}}$ Corresponding Author

\section{Introduction}

$N$-(2-carboxyl phenyl)-4-chloro anthranilic acid disodium salt (CCA), known as lobenzarit disodium, is a novel immunomodulatory drug useless in the treatment of acute inflammation ${ }^{1}$ but experimentally very useful in the treatment of chronic inflammatory auto-immune diseases such as rheumatoid arthritis $^{2}$ and diabetes. ${ }^{3}$ Its mechanism of action may be related to its capacity to enhance the $\mathrm{T}$ suppressor/ $\mathrm{T}$ helper lymphocyte ratio. ${ }^{4}$ However, from a molecular point of view the nature of the effect remains unclear.

CCA is a radical scavenging molecule derived from anthranilic acid ${ }^{5}$ which as far as is known shares structural features with known inhibitors of the guanylate cyclase pathway, such as chlorpromazine and methylene blue. Considering the crucial role of cyclic nucleotides in many of the activation processes of the immune system ${ }^{6}$ we decided to investigate the possible effect of CCA upon the generation of guanosine $3^{\prime}, 5^{\prime}$-cyclic monophosphate (cGMP) and the closely related nitric oxide (NO) metabolic pathway.

Two major nitric oxide synthases (NOS) have been reported: the inducible pathway (iNOS), that is mainly dependent on inflammatory stimuli, ${ }^{7}$ and the constitutive pathway (cNOS), that is controlled by calmodulin and cytosolic calcium levels. ${ }^{8,9}$ Both enzymes are used by Larginine in the presence of molecular oxygen to produce $\mathrm{L}$-citrulline and $\mathrm{NO},{ }^{10}$ although the distinguishable kinetic effects of the $\mathrm{CNOS}^{11}$ enable it to mediate in the generation of cGMP.?
cGMP, in particular, is known to be responsible for many immune inflammatory processes including macrophage activation, ${ }^{12}$ lymphocyte proliferation, ${ }^{13}$ vascular smooth muscle relaxation, ${ }^{14}$ mast cell degranulation, ${ }^{15}$ chemotaxis ${ }^{16}$ and platelet aggregation, ${ }^{17}$ and adhesion to endothelium. ${ }^{18}$ Therefore we investigated the effect of CCA upon the constitutive NO-cGMP metabolic pathways, in order to gain more insight into the pharmacodynamics of CCA, which might explain its therapeutic proficiency in the treatment of chronic inflammatory diseases.

\section{Materials and Methods}

Chemicals: CCA was synthesized by Dr R. Pellón and colleagues at the Center of Pharmaceutical Chemistry in Havana, Cuba. ${ }^{19}$ The radioimmunoassay kit for cGMP determinations and ${ }^{14} \mathrm{C}$-labelled L-arginine were obtained from Amersham International. The specific NOS inhibitor $\mathrm{L}-$ $N^{\mathrm{G}}$-monomethyl arginine (L-NMMA) was a kind of gift from Dr S. Moncada at Wellcome Research Laboratories. All other chemicals were purchased from Sigma.

Cytosol preparation: Brains of male SpragueDawley rats weighing $180-200 \mathrm{~g}$ were used as the best source for the conversion of cytosol into both guanylate cyclase and cNOS. As described previously, ${ }^{2}$ after decapitation rat forebrains were extracted and washed in ice-cold sucrose buffer (sucrose 0.32 M, HEPES $10 \mathrm{mM}$, DL-dithiothreitol 
$1 \mathrm{mM}, \mathrm{pH} 7.4)$, and thereafter homogenized in an appropriate buffer at $\mathrm{pH} 7.4$ containing Tris- $\mathrm{HCl}$ $(50 \mathrm{mM})$, EDTA $(0.1 \mathrm{mM})$, EGTA $(0.1 \mathrm{mM})$, dithiothreitol $(0.5 \mathrm{mM})$, phenylmethylsulphonyl fluoride $(1 \mathrm{mM})$, pepstatin $\mathrm{A}(1 \mu \mathrm{M})$ and leupeptin $(2 \mu \mathrm{M})$. Once extracted, the cytosol samples were kept at $0-4^{\circ} \mathrm{C}$ for no longer than $15 \mathrm{~min}$ before assay of cGMP and L-citrulline production.

\section{Biochemical assays:}

cGMP assay. According to previous reports, $150 \mu \mathrm{l}$ of cytosol were mixed with $50 \mu \mathrm{l}$ of a buffer containing Tris $(25 \mathrm{mM}), \mathrm{MgCl}_{2}(5 \mathrm{mM})$, Larginine $(100 \mu \mathrm{M}), \mathrm{CaCl}_{2}(2 \mathrm{mM}), 3$-isobutyl-1methyl xanthine (1 mM), GTP $(5 \mathrm{mM})$ and CCA $(1000,100,10$ or $0 \mu \mathrm{M})$. Total cGMP level in each fraction was quantified after $10 \mathrm{~min}$ of incubation at $37^{\circ} \mathrm{C}$ by using RIA following the manufacturer's instructions.

$\left[{ }^{14} \mathrm{C}\right]$-L-Citrulline assay. As described elsewhere, ${ }^{20}$ $25 \mu \mathrm{l}$ of cytosol were mixed with $100 \mu \mathrm{l}$ of an appropriate buffer at $\mathrm{pH} 7.4$ containing $\left[{ }^{14} \mathrm{C}\right]-\mathrm{L}$ arginine, Tris- $\mathrm{HCl}(50 \mathrm{mM})$, L-arginine $(100 \mu \mathrm{M})$, $\mathrm{NADPH}(100 \mu \mathrm{M}), \mathrm{CaCl}_{2}(2 \mathrm{mM})$ and CCA $(3000$, $300,30,3$ or $0 \mu \mathrm{M})$. Final amount of $\left[{ }^{14} \mathrm{C}\right]$-citrulline generated after $10 \mathrm{~min}$ of incubation at $37^{\circ} \mathrm{C}$ was determined in each fraction by liquid scintilliation counting coupled with a set of columns for ionic exchanging chromatography (Biorack).
Statistical analysis: All values were expressed as mean \pm standard deviation. The number of experiments $(n)$ is also shown for each case and was never less than three replicate experiments. Significant differences between the control group and the test groups was assessed using Student's $t$ test comparison; $p$ values less than 0.05 or 0.01 were considered significantly different.

\section{Results}

After 10 min of cytosol incubation at $37^{\circ} \mathrm{C}$ with the appropriate buffer, CCA spontaneously inhibited the generation of CGMP (Table 1). This inhibition clearly shows a concentration-dependent shape in the range between 0.01 and $1 \mathrm{mM}$ of CCA. A 100\% inhibition of the total amount of cGMP generated was reached at $1 \mathrm{mM}$ of CCA. To assess the real amount of cGMP produced in $10 \mathrm{~min}$, in each case the basal cGMP level (background) was subtracted.

Further results demonstrated that CCA is also capable of inhibiting, in a concentration-dependent manner, the constitutive generation of $\mathrm{L}$ citrulline after $10 \mathrm{~min}$ of cytosol incubation at $37^{\circ} \mathrm{C}$ with the appropriate buffer (Table 2). This finding indicates an inhibitory activity in the NOS metabolic pathway which reaches a maximum of more than $70 \%$ of the inhibition achieved by the specific antagonist L-NMMA.

It should be noted also that CCA when present at $3 \mathrm{mM}$ scarcely reaches the $70 \%$ of the cNOS

Table 1. Inhibitory effect of CCA upon the guanylate cyclase activation pathway

\begin{tabular}{|c|c|c|c|c|c|c|}
\hline & $\begin{array}{l}\text { Background } \\
\text { (at time 0) }\end{array}$ & $\begin{array}{c}+\mathrm{CCA} \\
(0 \mathrm{mM})\end{array}$ & $\begin{array}{c}+\mathrm{CCA} \\
(0.01 \mathrm{mM})\end{array}$ & $\begin{array}{c}+ \text { CCA } \\
(0.1 \mathrm{mM})\end{array}$ & $\begin{array}{c}+\mathrm{CCA} \\
(1 \mathrm{mM})\end{array}$ & $\begin{array}{c}\text { + L-NMMA } \\
(0.05 \mathrm{mM})\end{array}$ \\
\hline $\begin{array}{l}\text { cGMP } \\
\text { (pmol) }\end{array}$ & $2.7 \pm 0.43$ & $12.4 \pm 1.11$ & $7.6 \pm 1.78^{*}$ & $3.4 \pm 0.26^{\dagger}$ & $2.0 \pm 0.02^{\dagger}$ & $4.7 \pm 0.80^{\dagger}$ \\
\hline $\begin{array}{l}\text { Inhibition } \\
(\%)\end{array}$ & - & - & 50.3 & 91.7 & 106.6 & 78.6 \\
\hline Replicates & $n=6$ & $n=5$ & $n=5$ & $n=3$ & $n=3$ & $n=6$ \\
\hline
\end{tabular}

${ }^{*} p<0.05$ and ${ }^{\dagger} p<0.01$ when compared with the production of cGMP in the control group (+CCA $0 \mathrm{mM}$ ). To assess the real amount of cGMP generated in $10 \mathrm{~min}$, the level of cGMP present at time zero (background), was for each case subtracted. Percentages of inhibition are calculated by comparison with the total cGMP generated after $10 \mathrm{~min}$ in the absence of CCA. L-NMMA was used as an additional control because of the involvement of the cNOS metabolic pathway in the generation of cGMP.

Table 2. Inhibitory effect of CCA upon the cNOS activation pathway

\begin{tabular}{lccccc}
\hline & $\begin{array}{c}+\mathrm{CCA} \\
(\mathrm{O} \mathrm{mM})\end{array}$ & $\begin{array}{c}+\mathrm{CCA} \\
(0.003 \mathrm{mM})\end{array}$ & $\begin{array}{c}+\mathrm{CCA} \\
(0.03 \mathrm{mM})\end{array}$ & $\begin{array}{c}+\mathrm{CCA} \\
(0.3 \mathrm{mM})\end{array}$ & $\begin{array}{c}+\mathrm{CCA} \\
(3 \mathrm{mM})\end{array}$ \\
\hline $\begin{array}{l}\text { NOS activity } \\
\text { (nmol/mg/min) }\end{array}$ & $137.7 \pm 3.1$ & $133.0 \pm 2.5$ & $112.5 \pm 1.8^{*}$ & $104.4 \pm 21.2^{*}$ & $38.1 \pm 7.4^{*}$ \\
Inhibition (\%) & 0 & 3.4 & 18.3 & 24.2 & 72.3 \\
Replicates & $n=6$ & $n=4$ & $n=4$ & $n=4$ & $n=3$ \\
\hline
\end{tabular}

${ }^{*} p<0.01$ when compared with the control group (+ CCA O mM). 
inhibition achieved by L-NMMA at $0.05 \mathrm{mM}$, whereas CCA at $1 \mathrm{mM}$ exceeds the inhibitory action of L-NMMA at $0.05 \mathrm{mM}$ in cGMP generation.

\section{Discussion}

Considering that the inhibition of the guanylate cyclase system by CCA proved to be sufficient to reduce cGMP levels by $50 \%$ even at $0.01 \mathrm{mM}$, this action will probably have biological significance in terms of its molecular pharmacodynamics when in vivo conditions are considered.

Curiously, in our system L-NMMA (0.05 mM) does not abrogate the production of cGMP to the same extent as is observed for NO generation. This could be either because there is another NO-independent mechanism for guanylate cyclase stimulation ${ }^{21}$ or because L-NMMA $(0.05 \mathrm{mM})$ actually fails to affect NO generation, leaving a low level of cNOS activity. In any case, the results showing the inhibitory action of CCA upon the generation of NO are consistent and could provide an explanation for the inhibition of cGMP production achieved by CCA. However, for the cNOS system the inhibitory potential of CCA at $3 \mathrm{mM}$ seems to be slightly lower, reaching $70 \%$ of the inhibition caused by L-NMMA at $0.05 \mathrm{mM}$.

Regarding the fact that CCA ( $1 \mathrm{mM})$ is able to inhibit cGMP generation to a greater extent than is seen by L-NMMA $(0.05 \mathrm{mM})$, and furthermore CCA $(3 \mathrm{mM})$ has a lower inhibitory action than $\mathrm{L}$ NMMA $(0.05 \mathrm{mM})$ upon the generation of NO, it is possible that in addition to cNOS inhibition, CCA has another inhibitory effect on the NOcGMP metabolic pathway. Such additional inhibition (25\%) has indeed been observed when an exogenous NO-releasing molecule (SNAP) was used as a cNOS-independent mechanism for guanylate cyclase stimulation (data not shown). That could be either due to a NO scavenger activity (depending on its nitrosable diphenylamine nitrogen) or to a direct inhibition of the guanylate cyclase enzyme (by comparison of its structural similarities with the known guanylate cyclase inhibitor methylene blue).

It could be important also to elucidate the mechanism by which CCA inhibits cNOS activity. The calcium-calmodulin dependence of the cNOS, ${ }^{8}$ the strong calcium chelating properties of CCA (Dr R. Pellón, personal communication, and Reference 19) and the structural resemblance of CCA with chlorpromazine (a calmodulin antagonist that recently has been reported to be an inhibitor for the activation of brain cNOS and a suppressor for LPS-induction of iNOS in the lung $^{22}$ ) have given weight to the idea that the calcium-calmodulin system is the predominant system involved in such inhibition.

In summary, considering the role of cNOS for mediating the induction of the iNOS ${ }^{22,23}$ in addition to the capacity for high NO levels to cause tissue damage ${ }^{24}$ and to suppress $\mathrm{T}$ helper type 1 cells $^{25}$ (which often work like ' $\mathrm{T}$ suppressor cells' for antibody production), it is possible to suggest that most of the therapeutic effects of CCA are to a great extent due to its capacity to inhibit the NO-cGMP metabolic pathway, which is known to play a critical role in arthritis ${ }^{26}$ and diabetes. ${ }^{27}$ Additionally, since most of the cNOS share their calcium-calmodulin dependence, ${ }^{28}$ there are many other potential effects of CCA that should be investigated in future. In fact, there are several actions of CCA that potentially could be explained by such effects. The results of the present work may indicate a new course for investigations of the pharmacodynamics of lobenzarit disodium that may result in the search for novel strategies for the therapy of chronic inflammatory auto-immune diseases.

\section{References}

1. Tanemura M, Nakano $\mathrm{T}$, Ohsugi $\mathrm{Y}$, et al. Effect of an immunomodulator 'lobenzarit disodium (CCA)' in various models of inflammation. Jap J Inflammation 1984; 4: 239-242.

2. Itokazu M, Tanaka S. Anti-arthritic effect of a newly synthesized immuno modulating drug: lobenzarit. Jap J Inflammation 1983; 3: 244-247.

3. Iwakiri R, Nagafuchi S. Inhibition of streptozocin-induced insulitis and diabetes with lobenzarit in CD-1 mice. Diabetes 1989; 38: 558-561.

4. Matsuno H, Matsushita I, Kadowaki KM, et al. Effects of lobenzarit disodium on lymphocyte subsets related to the onset of collagen-induced arthritis. Int J Immunotherapy 1992; VI(2): 67-75.

5. Cynshi O, Saitoh M, Cynshi F, Tanemura M, Hata S, Nakano M. Anti-oxidative profile of lobenzarit disodium. Biochem Pharmacol 1990; 39: 2117-2122.

6. Watson J. The influence of intracellular levels of cyclic nucleotides on cell proliferation and the induction of antibody synthesis. J Exp Med 1975; 141: $97-111$.

7. Stuehr DJ, Cho HJ, Kwon NS, Weise M, Nathan CF. Purification and char acterization of the cytokine-induced macrophage nitric oxide synthase: an FAD- and FMN-containing flavoprotein. Proc Natl Acad Sci USA 1991; 88 7773-7777.

8. Bredt DS, Snyder SH. Isolation of nitric oxide synthase, a calmodulin requiring enzyme. Proc Natl Acad Sci USA 1990; 87: 682-685.

9. Knowles R, Palacios M, Palmer R, Moncada S. Formation of nitric oxide from L-arginine in the central nervous system: a transduction mechanism for stimulation of soluble guanylate cyclase. Proc Natl Acad Sci USA 1989, 86: $5159-5162$.

10. Leone A, Palmer R, Knowles R, Francis P, Ashton D, Moncada S. Constitutive and inducible nitric oxide synthase incorporate molecular oxygen into both nitric oxide and citrulline. J Biol Chem 1991; 226 23790-23795.

11. Knowles R, Palacios M, Palmer R, Moncada S. Kinetic characteristics of nitric synthase from rat brain. Biochem J 1990; 269: 207-210.

12. Bromberg Y, Pigk E. Cyclic GMP metabolism in macrophages. Cell Immunol 1980; 52: 73-83.

13. Hadden J, Hadden E, Haddeox M, Goldberg N. Guanosine $3^{\prime}, 5^{\prime}$-cyclic monophosphate: a possible intracellular mediator of mitogenic influences in lymphocytes. Proc Natl Acad Sci USA 1972; 69: 3024-3027.

14. Gruetter C, Barry B, McNamara D, Gruetter D, Kadowitz P, Ignarro L. Relaxation of bovine coronary artery and activation of coronary arteria guanylate cyclase by nitric oxide, nitroprusside, and a carcinogenic nitrosamine. J Cyclic Nucleotide Res 1979; 5: 211-224.

15. Salvemini D, Masini E, Anggard E, Mannaioni P, Vane J. Synthesis of a nitric oxide-like factor from $L$-arginine by rat serosal mast cells: stimulation of guanylate cyclase and inhibition of platelet aggregation. Biochem Biophys Res Commun 1990; 169: 596-601. 
16. Kaplan S, Billiar T, Curran R, Zdziarski U, Simmons R, Basford R. Inhibition of chemotaxis with $N^{G}$-monomethyl-L-arginine: a role for cyclic GMP. Blood 1989; 74: 1885-1887.

17. Mellion B, Ignarro L, Ohlstein E, Pontecorvo E, Hyman A, Kadowitz P. Evidence for the inhibitory role of guanosine $-3^{\prime}, 5^{\prime}$-monophosphate in $\mathrm{ADP}$-induced human platelet aggregation in the presence of $\mathrm{NO}$ and related vasodilators. Blood 1981; 57: 946-955.

18. Radomski M, Palmer R, Moncada S. The role of nitric oxide and CGMP in platelet adhesion to vascular endothelium. Biochem Biophys Res Commun 1987; 148: 1482-1489.

19. Pellóon R, Millian V, Carrasco R. Procedure for the synthesis of sub stituted N-phenylanthranilic acids. 1992 Cuban patent No. 22105.

20. Palacios M, Knowles R, Palmer R, Moncada S. Nitric oxide from L-arginine stimulates the soluble guanylate cyclase in adrenal glands. Biochem Biophys Res Commun 1989; 165: 802-809.

21. Beasley D, McGuiggin M. Interleukin 1 activates soluble guanylate cyclase in a human vascular smooth muscle through a novel nitric oxide-independent pathway. J Exp Med 1994; 179: 71-80.

22. Palacios M, Padron J, Glaria L, et al. Chlorpromazine inhibits both the constitutive nitric oxide synthase and the induction of nitric oxide synthase after LPS challenge. Biochem Biophys Res Commun 1993; 196: 280-286.

23. Glaria L, Delgado R, Rojas A, et al. Role of brain nitric oxide synthase in the endotoxic shock. In: Moncada S, Feelish M, Busse R, Higgs EA. eds. Biology of Nitric Oxide. Volume 3: Clinical and Physiological Aspects. London: Portland Press Ltd, 1994; 302-305.

24. Hibbs J, Vavrin Z, Taintor R. L-arginine is required for the expression of the activated macrophage effector mechanism causing selective metabolic inhibition of target cells. J Immunol 1987; 138: 550-565.

25. Taylor-Robinson A, Liew F, Severn A, et al. Regulation of the immune response by NO differentially produced by $\mathrm{T}$ helper type 1 and $\mathrm{T}$ helper type 2 cells. Eur J Immunol 1994; 24: 980-984

26. Ialenti A, Moncada S, Di Rosa M. Modulation of adjuvant arthritis by endogenous nitric oxide. Br J Pharmacol 1993; 110: 701-706

27. Corbett J, Wang J, Hughes J, et al Nitric oxide and cGMP formation induced by interleukin $1 \beta$ in islets of Langerhans. Biochem J 1992; 287: 229-235

28. Sievert P, Wright S, Larric J. Examination of brain type of nitric oxide synthase expression in non-neural tissues by RT-PCR. Clontechniques 1992; 7: 1-3.

\section{Received 9 May 1995;}

accepted in revised form 13 July 1995 


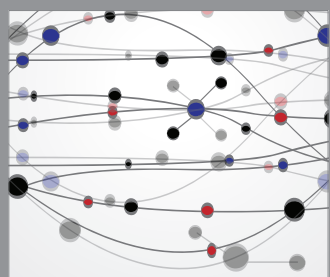

The Scientific World Journal
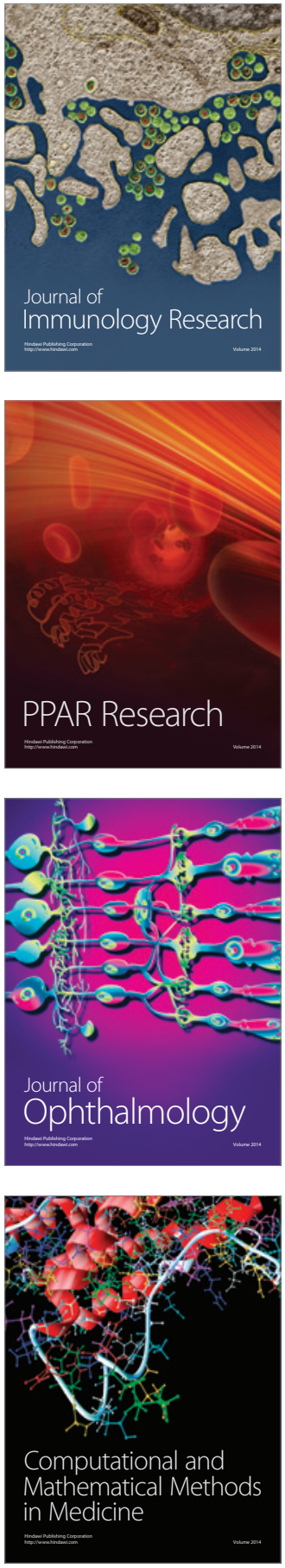

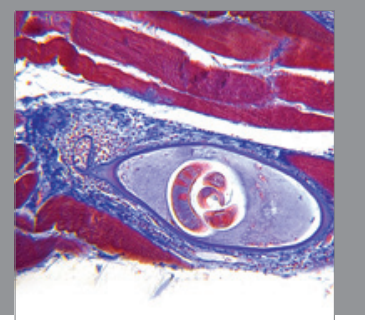

Gastroenterology

Research and Practice
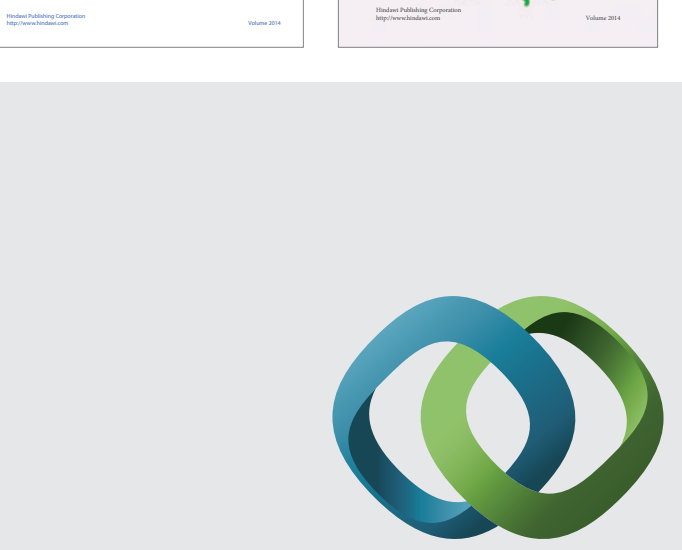

\section{Hindawi}

Submit your manuscripts at

http://www.hindawi.com
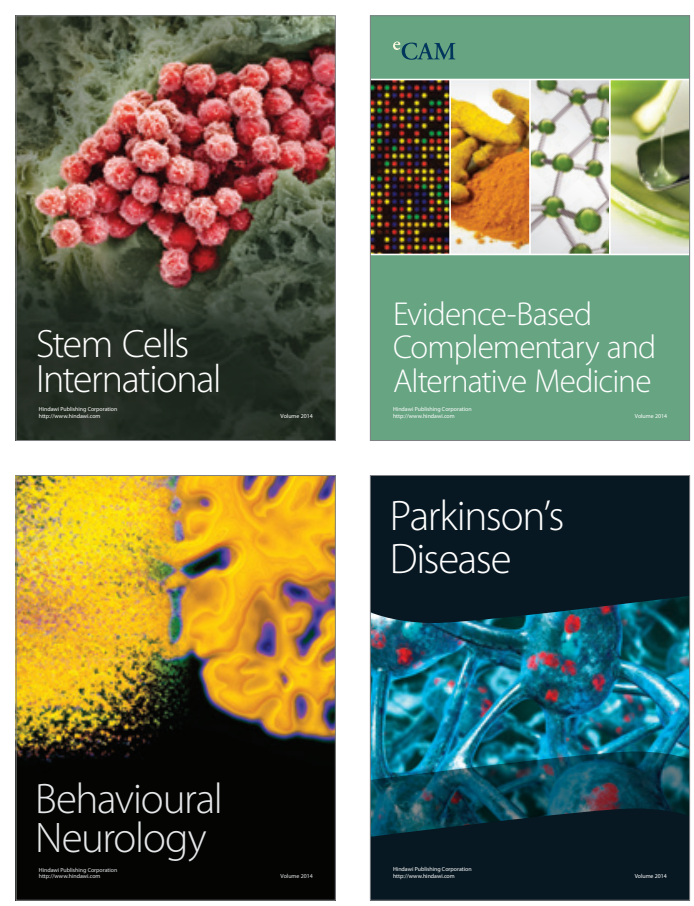

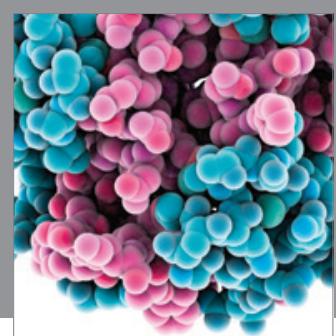

Journal of
Diabetes Research

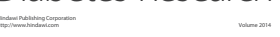

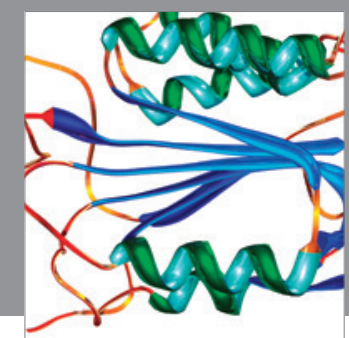

Disease Markers
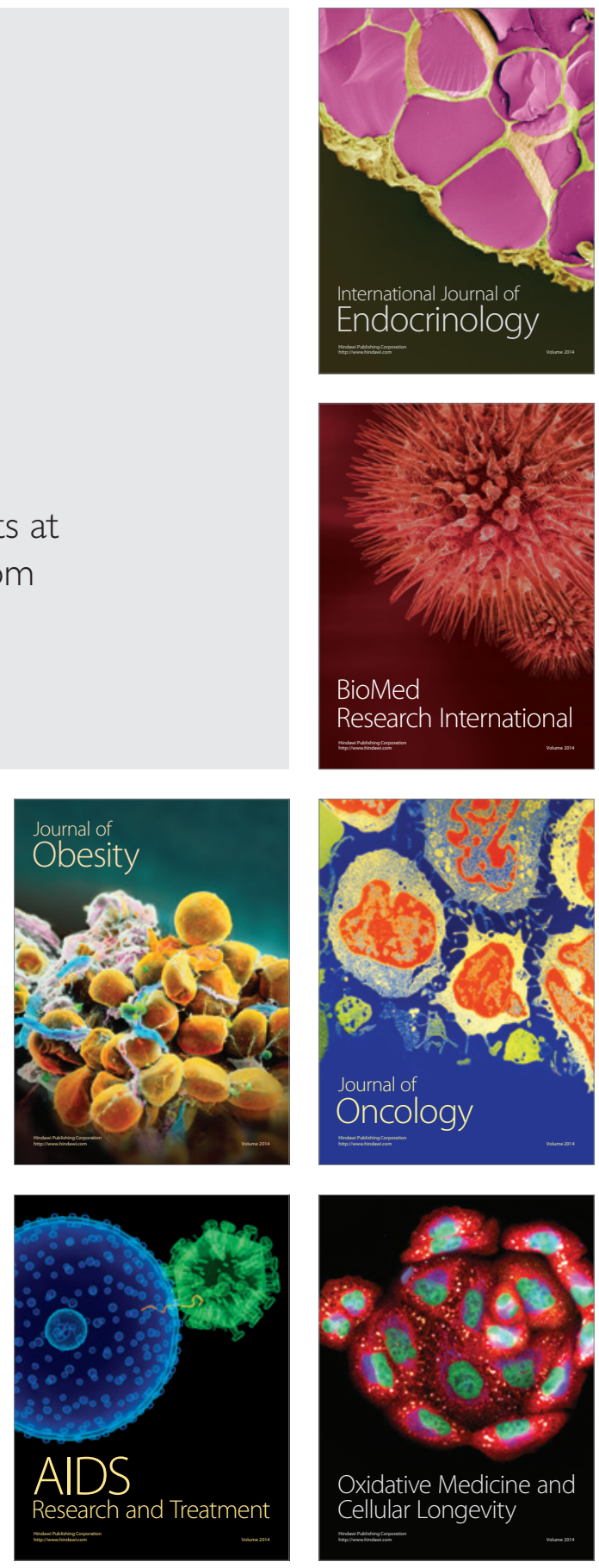